Bond University

Research Repository

\title{
Customer engagement behavior in individualistic and collectivistic markets
}

\author{
Roy, Sanjit Kumar; Balaji, M.S.; Soutar, George; Lassar, Walfried M; Roy, Rajat
}

Published in:

Journal of Business Research

DOI:

10.1016/j.jbusres.2017.06.001

\section{Licence:}

CC BY-NC-ND

Link to output in Bond University research repository.

Recommended citation(APA):

Roy, S. K., Balaji, M. S., Soutar, G., Lassar, W. M., \& Roy, R. (2018). Customer engagement behavior in individualistic and collectivistic markets. Journal of Business Research, 86, 281-290.

https://doi.org/10.1016/j.jbusres.2017.06.001

\footnotetext{
General rights

Copyright and moral rights for the publications made accessible in the public portal are retained by the authors and/or other copyright owners and it is a condition of accessing publications that users recognise and abide by the legal requirements associated with these rights.
}

For more information, or if you believe that this document breaches copyright, please contact the Bond University research repository coordinator. 


\title{
CUSTOMER ENGAGEMENT BEHAVIOR IN INDIVIDUALISTIC AND \\ COLLECTIVISTIC MARKETS
}

\begin{abstract}
Managing customer engagement behavior (CEB) is a strategic priority for firms to build and sustain long-term customer-firm relationships. This research examines the different types of customer engagement behavior (i.e. augmenting CEB, co-developing CEB, influencing CEB and mobilizing CEB). The study also examines the relationship between service fairness, different forms of trust (cognitive and affective), value-in-use (ViU) and CEB. The research model was tested across two developed (USA and Australia) and two developing economies (India and China). Results suggest that CEB is a higher-order construct and its structure is consistent across the developed and developing markets. In terms of cross-cultural differences, service fairness has a stronger influence on affective trust in the developing economies as compared to developed economies. Findings indicate that to motivate customers in developed and developing markets to engage, service providers need to treat them fairly, build cognitive and affective trust and understand how they create value-in-use. Keywords: Customer engagement behavior, Service fairness, Affective trust, Cognitive trust
\end{abstract}




\section{Introduction}

Customer engagement (CE) is receiving increased attention, as engaged customers are less price sensitive, resist switching, actively participate in new product and service development and advocate for organizations (Hollebeek, Srivastava, \& Chen, 2016). Further, new technologies, such as social media platforms and connected technologies, have led to the adoption of customer-centric strategies that build and sustain long-term organizationcustomer relationships (Verhoef et al., 2010), increasing the importance of customer interactions that co-create value (Ostrom et al., 2015), which can be termed customer engagement behaviors (CEBs).

Given its importance, the Marketing Science Institute (2016) has included customer engagement as a key research priority in recent years. There has also been considerable effort to measure customer engagement and identify its antecedents and consequences (Hollebeek et al., 2016; Pansari \& Kumar, 2016). However, there is little understanding of the types of CEBs customers display (Jaakkola \& Alexander, 2014). These behavioral expressions are different manifestations of the same underlying construct (i.e. CEB). Our understanding of these behaviors is important and can be improved by identifying and examining their antecedents (Van Doorn et al., 2010), especially as organizations have limited understanding of the resources customers contribute to the value creation process (Hoyer et al., 2010). Thus, the primary objective of this study was to examine the different types of CEBs suggested by Jaakkola and Alexander (2014) (i.e. augmenting CEB, co-developing CEB, influencing CEB and mobilizing CEB) and to identify their antecedents. Further, while most consumer studies have been undertaken in developed economies (Maheswaran \& Shavitt, 2000; Dekimpe, 2009), Burgess and Steenkamp (2013) have recently argued developing markets are likely to provide important additional information. Consequently, this study was undertaken in developed and developing markets to see if this was the case in a CEB context. 
Traditionally, service fairness and trust have been considered strategic levers that organizations can use to create positive customer responses, such as loyalty and positive word-of-mouth (a form of CEB). While there is a connection between service fairness and trust (Roy, Devlin, \& Sekhon, 2015), the psychological mechanisms through which fairness affects trust may be seen more clearly by using a two-dimensional conceptualization of trust (i.e. cognitive and affective trust) (Yang, Mossholder, \& Peng, 2009). However, more research is needed into the relationship between fairness and this two-dimensional view of trust (Dirks \& Ferrin, 2002). In particular, firms need to understand the role service fairness and trust play in influencing in customers' extra role behaviors, as these roles have evolved in recent years and are not now limited to repurchase behavior or positive word-of-mouth. Today's customers can also actively participate in co-production, co-creation and service delivery (Grönroos \& Voima, 2013), which means it is important to expand our understanding of the CEBs related to these expanded roles. Further, as noted earlier, given the increasing importance of developing markets, it was seen as desirable to examine the relationship between service fairness and trust and their relationships with customer engagement behavior in developed and developing markets.

Before discussing the study undertaken to do this, a theoretical background is provided and a research model and some suggested hypotheses are discussed. The research approach is then outlined, after which the results obtained are discussed. Finally, the study's theoretical contributions and managerial implications are discussed and future research directions are suggested.

\section{The theoretical background}

\subsection{Customer engagement behaviors}

“Engagement” has received extensive attention across many disciplines, including marketing (Pansari \& Kumar, 2016). Researchers have suggested CE might be a process 
(Bowden, 2009), a psychological state (cognitive, affective and behavioral) (Brodie et al., 2011) or a behavioral manifestation (Verleye et al., 2016). CE has been seen as an aggregation of the ways through which customers influence the value co-creation process beyond mere purchase (Brodie, et al., 2011; Jaakkola \& Alexander, 2014), which led van Doorn et al. (2010; p. 254) to define CEBs as “customers’ behavioral manifestations towards the brand or firm, beyond purchase, resulting from motivational drivers." Such a focus has been widely adopted (Hollebeek et al., 2016), with CEBs often defined as behavioral manifestations of customers' engagement with an organization beyond the purchase process (Verleye et al., 2016).

Consistent with van Doorn et al.'s (2010) and Brodie et al.’s (2011) suggestions, Jaakkola and Alexander (2014) examined CEB through a voluntary resource contribution lens. They suggested customers provide many resources, including time, money and effort and actions, which affect organizations and their customers directly and indirectly. Following Jaakkola and Alexander's (2014) suggestions, four types of CEBs were considered, namely:

1. Augmenting CEBs, which occur when a customer's contributions augment an offering. For example, customers might create content on social media that supports an organization's offerings.

2. Co-developing CEBs, which occur when a customer's contributions help a firm's development processes. For example, customers might provide new product or service ideas.

3. Influencing CEBs, which occur when a customer's contributions affect or change other customers' perceptions and/or behavior. For example, customers’ might recommend an offering online or offline. 
4. Mobilizing CEBs, which occur when customers' contributions mobilize other stakeholders' behaviors towards the organization. For example, customers might convince other customers to buy an offering.

\subsection{Value-in-use}

Service dominant logic suggests value is co-created with customers as 'value-in-use' (ViU) rather than being embedded in tangible goods (Ranjan \& Read, 2016). However, there is no consensus as to how ViU should be measured (MacDonald et al., 2011), even though $\mathrm{ViU}$ is seen as the missing link between service quality and relationship outcomes (MacDonald et al., 2011). Edvardsson et al. (2011) defined ViU as a customer's experiential evaluation of a service and suggested it is based on customers' individual motivations, competencies, actions and performance. The central element of $\mathrm{ViU}$ is value creation over time as customers use an offering. Consistent with this view, Grönroos and Voima (2013, p. 3) suggested "value creation (is) an ongoing process which encompasses customers' experiences, logic and ability to extract value out of products and other resources used (create value-in-use)". ViU measures the extent to which customers feel better-off (i.e. positive value) or worse-off (i.e. negative value) through their experiences. Thus, ViU is customerdriven and accumulates over time, with customers being seen as value creators and not merely as people who assess or determine value (Ranjan \& Read, 2016).

\subsection{Cognitive and affective trust}

Trust is a multifaceted construct that is fundamental to building and maintaining relationships. Customers' trust has cognitive and affective aspects (McAllister, 1995). Dirks and Ferrin (2002) suggested more research is needed to better understand the distinction between cognitive and affective trust so as to allow a multi-faceted examination of trust and its impact on outcomes. Bringing cognitive and affective forms of trust into fairness research should strengthen trust and fairness research (Lewicki et al., 2005). The rational element 
(cognitive trust) is rooted in a person's knowledge and understanding of another party's capabilities (Castaldo, 2007; Sekhon et al., 2013). In B2C service relationships, cognitive trust is a customer's confidence or willingness to rely on service providers (Johnson \& Grayson, 2005). Cognitive trust is based on shared values, experiences and information cues between customers and service providers that lessen the uncertainty in such relationships. Affective trust, on the other hand, develops over time as a result of customers' interactions, which can create deep emotional bonds (Harms, Bai, \& Han, 2016) if providers show care and concern (Johnson \& Grayson, 2005). Affective trust results from personality, sensory cues and experiences when interacting with service providers. Thus, affective trust is at a higher level than cognitive trust (Johnson \& Grayson, 2005; Kumar Ranganathan et al., 2013).

\subsection{Perceived service fairness}

Perceived fairness is an important aspect of organizations' relationship marketing strategies (Roy, Devlin, \& Sekhon, 2015). According to Oliver (1997), fairness is the perceived 'rightness' that comes from customers' evaluations of the inputs and outputs in their exchange relationships. Similarly, Seiders and Berry (1998, p. 9) defined service fairness as “a customer's perception of the degree of justice in a service firm's behavior”. Fairness is the fundamental basis on which people evaluate their relationship with other people and with institutions (Clemmer \& Schneider, 1996) and, because of their intangibility, fairness is crucially important in service contexts (Zhu \& Chen, 2012). Consistent with prior research into the subjective nature of fairness, service fairness can be defined as customers' subjective judgments about the fairness of their relationships with a service provider. 


\subsection{Research model and hypotheses}

\subsubsection{Service fairness and trust}

Trust plays a major role in the formation of service relationships (Morgan \& Hunt, 1994) and a lack of trust has negative outcomes (Tomlinson \& Mayer, 2009). Prior research has suggested people's trust in other people and organizations develops through sustained fair treatment, such as B2C service relationships (Lewicki \& Bunker, 1995). Indeed, trust is seen as an outcome of fairness (Aryee et al., 2002; Khazanchi \& Masterson, 2011), a view supported by social exchange theory (SET) (Blau, 1964). According to SET, the fair treatment of one party by another party creates trust and there is empirical evidence support for this view (Roy et al., 2015). However, little research has examined the relationship between service fairness and different forms of trust (i.e. cognitive and affective trust), which led Lewicki and Bunker (1995) to suggest our understanding of this relationship would be incomplete if we did not acknowledge the relationship between fairness and different forms of trust, suggesting:

$H_{1}$ : Service fairness has a positive impact on cognitive and affective trust.

\subsubsection{Trust and value-in-use}

As already noted, cognitive trust is rational thought about a provider's knowledge and capabilities (Sekhon et al., 2013); while affective trust comes from emotional bonds that develop over time (Harms et al., 2016). Further, a core ViU proposition is that value is created over time through a customer's cognitive and experiential interactions with a provider (Grönroos \& Voima, 2013; Vargo \& Lusch, 2016). Thus, ViU is about experience, relationship, and personalization and has cognitive and affective elements (Ranjan \& Read, 2016). A number of studies have suggested the impact trust has on relationship outcomes is contingent on the value created. Trust creates value, as it provides relational benefits from sustained interactions with a provider that is seen as competent, benevolent and committed to 
solving problems (Sirdeshmukh, Singh, \& Sabol 2002). Indeed, Sirdeshmukh et al. (2002) found that, when customers trusted frontline employees and management practices, they felt they obtained better value, suggesting:

$H_{2}$ : Cognitive and affective trust has positive impacts on value-in-use.

\subsubsection{Trust, customer engagement behavior and ViU}

Trust, which has cognitive and affective aspects, is a critical antecedent to CEBs (van Doorn et al., 2010; Brodie et al., 2011). Greater trust leads customers to engage in CEBs (De Matos \& Rossi, 2008) and to act as advocates for their providers (Gremler, Gwinner, \& Brown, 2001). As cognitive trust is based on customers' assessments of providers' competence, integrity and reliability, customers are more confident of their trusted providers, increasing their likelihood of engaging in CEBs (Zhu et al., 2013). Further, as affective trust is based on emotional bonds, customers are likely to reciprocate by engaging in CEBs, suggesting:

$H_{3}$ : Cognitive and affective trust have positive impacts on CEB.

Perceived value plays an important role in exchange processes and there is general agreement that perceived value is positively related to commitment and recommendation behaviors (Wu et al., 2014). Value-in-use suggests value is realized only when an offering is used. Thus, value is ultimately determined by customers' evaluations of their interactions with providers (MacDonald et al., 2011). When value is realized during use, customers are likely to participate in engagement behaviors (Brodie et al., 2011), suggesting:

$H_{4}$ : Value-in-use has a positive impact on CEB.

\subsubsection{Relationships between perceived service fairness, trust, CEB and ViU}

Scholars have suggested the role identity plays in determining when fairness matters should be examined (Clayton \& Opotow, 2003). Although fairness research has implicitly considered identity's role, it has largely ignored the fact that identity can be fluid, take 
multiple forms and have evaluative connotations. According to the Accessible Identity Model, people's likelihood of engaging in fairness reasoning is a function of the type of self (e.g. social versus personal) that dominates their working self-concept (Skitka, 2003).

A number of fairness theorists have suggested people care about fairness because it serves their need to belong and validates their social standing in groups they deem important (Lind \& Tyler, 1988; Tyler \& Lind, 1992). For example, equity theorists claim people care about fairness as it serves their long term personal interest (Adams 1965; Skitka 2003). Prior research has suggested people's perception of fairness changes when they are directly affected (Mikula et al., 1998). Indeed, research evidence shows that, when interdependent (vs. independent) self-construal is activated, people react more favorably to decision outcomes following a fair procedure (Holmvall \& Bobocel, 2008). There is evidence that self-identities can be culturally constructed and that cultural differences influence fairness perceptions (Clayton \& Opotow, 2003).

Early research found Indians placed a different emphasis on interpersonal responsibilities and situational context while considering notions of fairness than did North Americans (Miller, 1997). Thus, in collectivist societies, people may perceive a need-based distribution of resources as fairer than a merit driven resource allocation, while the opposite may be true in individualistic countries (Murphy-Berman \& Berman, 2002). Further, past research has suggested people may consider an outcome distribution as being fair to their personal self but not to their group as a whole (Taylor et al., 1990).

Indeed, in collectivist societies, people may care more about the fairness of outcomes for relationship reasons (Fischer, 2013). In support of this, evidence shows collective fairness perceptions are more meaningful in group oriented cultures, like those in East Asia (Hayashi \& Sekiguchi, 2006). Similarly, collectivists show more moral obligations towards group members (Chen, Peng, \& Saparito, 2002) and fairness can be affected by moral values 
(Brockner, De Cremer, van den Bos, \& Chen, 2005; Fischer 2013). Finally, evidence shows that organizational commitment created by fairness perceptions is greater in collectivist societies (Cohen \& Avrahami, 2006). Fairness perceptions are also positively related to work engagement, an effect mediated through trust (Agarwal, 2014). Similarly, the positive effect that fairness has on perceived value and satisfaction seem to be mediated through trust (Zhu \& Chen, 2012), suggesting:

$H_{5}$ : Service fairness has a stronger influence on (a) cognitive and (b) affective trust in countries with collectivist (rather than individualist) values.

The relationship between trust and attitude or behavior is interesting in individualistic and collectivist societies, as it can underlie cooperative behavior. Individualistic societies tend to demonstrate greater trust, as they cooperate with more transitory groups, while collectivist cultures demonstrate higher trust towards group members (Buchan et al., 2002; Chen et al., 2002). Thus, the notion of trust itself can differ across nations. For example, Americans seem to be more trusting than Japanese (Yamagishi, 1988; Buchan et al., 2002). Similarly, the USA seems to have more spontaneous trust, while China seems to have greater interpersonal distrust (Fukuyama, 1995; Chen et al., 2002). Evidence suggests trust drives sustained interactions with a service provider and leads to better value creation (Ranjan \& Read, 2016; Sirdeshmukh, Singh, \& Sabol 2002). Given these findings, customers should feel better-off and extract more value out of a relationship (create value-in-use), especially when the notion of trust itself is stronger, as in an individualistic society. Further, as customers feel more confident of their trusted providers, they are more likely to engage in CEB (Zhu et al., 2013), albeit such a relationship will be stronger when the notion of trust is higher. However, the relationship between value in use and CEB should be stronger in a collectivist society, based on the following arguments. Firstly, past research shows perceived value underlies commitment to an ongoing relationship (Wu et al., 2014). Secondly, collectivist societies 
have greater relational commitment than individualistic societies (Chen et al., 2002). As greater value creation motivates enhanced customer interaction (Ostrom et al., 2015), we would expect such a relationship to flourish in an environment that nurtures relational commitments (i.e., collectivistic society). Thus, it can be suggested:

$H_{6}$ : Cognitive and affective trust has a stronger influence on value-in-use in countries with individualist (rather than collectivist) values.

$H_{7}$ : Cognitive and affective trust has a stronger influence on customer engagement behavior in countries with individualist (rather than collectivist) values.

$H_{8}$ : Value-in-use has a stronger influence on customer engagement behavior in countries with collectivist (rather than individualist) values.

The study undertaken to examine these hypotheses drew on consumers' experience with luxury hotels that place greater emphasis on guests' experience and satisfaction. This is an increasingly important sector that has seen an exponential growth and expansion in recent years (Knox, 2008; Yang \& Lau, 2015), growing by 17\% in 2014-15 (D’Arpizio et al., 2015). While the USA is the leader in the luxury hotels sector, such hotels in emerging markets, such as China and India, have attracted consumer attention in recent years due to rising disposable incomes and an increase in the number of international events. Indeed, these markets are estimated to make up around $10 \%$ of the global luxury hotel sector (PRNewswire, 2016). The increasing numbers of tourists coming to Australia has also led to a boom in luxury hotels, with recent reports suggesting as many as 60 luxury hotels are planned across Australia (JLL Real Views, 2016). Consequently, India, China, the USA and Australia were seen as appropriate countries within which to undertake this study. 


\section{Method}

\subsection{The measures}

Scales from prior research were used to measure most of the constructs. Distributive fairness, procedural fairness, interpersonal fairness and informational fairness, which are subdimensions of fairness, were measured using items suggested by Carr (2007) and Devlin et al. (2014). Cognitive trust was measured using McAllister's (1995) scale, while affective trust was measured using items suggested by Mayer and Davis (1999) and Sekhon et al. (2014). The value-in-use scale was adapted from Blocker (2011). The customer engagement behavior scale was measured using 16 items developed within this study and based on Jaakkola and Alexander's (2014) earlier research, which had identified the four customer engagement behavior types discussed earlier (i.e. co-developing, augmenting, influencing, and mobilizing behaviors). Table 1 provides information about the items.

\subsection{Survey procedure and participants}

The questionnaire, which asked about respondents' hotel experiences (a typical service interaction), was pre-tested on a convenience sample of 50 university students to see whether there were potential issues with flow, clarity or comprehension. This led to some minor changes. The revised questionnaire was administered in each country by qSample (www.qsample.com), an international marketing research company, through its online panel system. This firm was selected primarily because of its access to the populations of interest and the rigorous procedure it uses when selecting representative samples. A sample was drawn that was a reasonable representation of the relevant target population (people who were older than 18 years and had stayed in a luxury hotel in the 12 months prior to responding), with responses being obtained in four countries (Australia, the USA, India and China). A quota-based approach was used to ensure respondents represented the population of interest in each country as closely as possible. 
The same questionnaire and data collection methods were used in each country, although, while the USA, Australian and Indian questionnaires were in English, the Chinese questionnaire was translated into Mandarin and back translated into English by bilingual experts, as recommended by Malhotra, Agarwal, and Peterson (1996), to ensure accuracy and consistency with the original questionnaire. Following this, the original and translated questionnaires were reviewed by another bilingual expert for language (grammar, spelling, and vocabulary) and cultural appropriateness and administered by the research firm in each country. A total of 1259 usable responses were collected (435 from Australia, 396 from the USA, 204 from China, and 224 from India). Based on Soper's (2014) sample size calculator, the total number of responses required for model structure was found to be sufficient (the minimum sample recommended for structural equation modelling with 9 latent variables, 43 observed variables, a p-level of 0.05 and an anticipated size effect of 0.03 is 184).

More American respondents were females (53\%); most were more than 35 years (76\%) and employed (57\%). Approximately 51\% had visited a luxury hotel six or more times in the previous year and, on average, stayed between three and five nights. More Australian respondents were female (52\%); most were more than 26 years (89\%) and employed (61\%). Almost $67 \%$ had visited a luxury hotel six or more time and many stayed three or more days, perhaps reflecting geographic distance from Australia to many tourist destinations. Indian and Chinese respondents were different. Most were male (India: 67\%; China: 64\%), younger (between 26 and 35 years) (India: 56\%; China: 55\%) and were employed (India: 78\%; China: 83\%). A majority of the Indian respondents (94\%) had stayed more than three nights during their stay. Approximately 39\% of the Chinese respondents had stayed between five and six days (39\%). 


\subsection{Data analysis}

A partial least squares (PLS) approach to structural equation modeling (SEM) was used to test the various relationships. PLS-SEM is a component-based approach that can be used to predict key target variables (Hair et al., 2011). Unlike the covariance-based SEM approach, PLS-SEM does not rely on normality assumptions and does not require large sample sizes (Hair et al., 2011). In this case, the SmartPLS 3.0 program was used to estimate the model's parameters (Ringle, Wende, \& Becker, 2015).

\subsection{Common method bias}

As common method bias (CMB) can be problematic in cross-sectional surveys, procedural and statistical methods were used to examine this issue (Podsakoff et al., 2003). Procedurally, respondents were informed there was no right or wrong answers, asked to answer as honestly as possible and assured of anonymity (Podsakoff et al., 2003). Statistically, after the data collection, Harman's single-factor test was used, which showed the first factor explained 33\% of the total variance, well below the suggested $50 \%$ threshold. The marker variable approach recommended by Lindell and Whitney (2001) was also used. This did not show significant differences, suggesting CMB was not a major issue in this study.

\section{Results}

The two-step modeling approach recommended by Anderson and Gerbing (1988) was used to empirically assess the constructs' measurement properties (the outer model) and the structural (the inner) model. Consistent with this two-step approach, the measurement properties were examined first to assess reliability and validity, after which the structural model was estimated. The structural model was used to test hypotheses $\mathrm{H}_{1}-\mathrm{H}_{4}$ and a multigroup analysis approach using the Welch-Satterthwaite approach (Sarstedt et al., 2011) was used to assess cross-cultural differences $\left(\mathrm{H}_{5}-\mathrm{H}_{8}\right)$. We drew on Henseler, Ringle, and 
Sarstedt's (2016) measurement invariance of composite models (MICOM) procedure to test measurement invariance before testing differences in the structural paths across the four countries.

\subsection{The constructs' measurement properties}

Reliability was assessed and convergent validity determined through the strength and significance of the factor loadings and by computing average variance extracted (AVE) scores (Fornell \& Larcker, 1981). As can be seen in Table 1, all of the loadings were satisfactory (greater than 0.50) and statistically significant (p < 0.01) (Hair et al., 2006). Further, discriminant validity was established, as the average variance extracted for each construct was greater than its shared variance with the model's other constructs (Fornell \& Larcker, 1981).

\section{[Insert Table 1 about here]}

The construct reliability coefficients for all of the constructs were greater than 0.70 and all of the AVE scores were greater than 0.50 (Hair et al., 2006), suggesting reliability and convergent validity. However, the four-suggested service fairness sub-dimensions did not seem to have discriminant validity, as their correlations ranged from 0.84 to 0.91 , some of which were higher than the square roots of their AVE scores. Consequently, an exploratory factor analysis was undertaken to better understand this construct's dimensionality. A parallel analysis suggested there was only a single factor, as did the eigenvalue test, as there was only one eigenvalue greater than one (11.84) that explained $70 \%$ of the variation in the data. This result is in line with Törnblom and Vermunt's (1999) and DeWitt et al.’s (2008) suggestion that people judge fairness in an overall way. Thus, service fairness was included as a single overall construct in the subsequent analysis. 


\subsection{The structural model}

A bootstrapping procedure with 5000 resamples was used to estimate the paths' significance (Hair et al., 2011) in the structural model. The estimated model was evaluated using a number of indices, including $\mathrm{R}^{2}$ values, average variance accounted for (AVA) scores, path coefficients, bootstrapping critical ratios and a redundancy analysis.

The usefulness of the model was established by combining predictive relevance and the strength of the path coefficients. As can be seen in Figure 1 , all of the $\mathrm{R}^{2}$ values were greater than 0.10 (Falk \& Miller, 1992). Similarly, the average variance accounted for (AVA) scores exceeded the suggested 0.10 cut-off (Falk \& Miller, 1992) (Australia: 0.48; USA: 0.43, India: 0.57; China: 0.75), suggesting the model had good predictive power.

\section{[Insert Figure 1 about here]}

In addition, the cross-validated communalities $\left(\mathrm{H}^{2}\right)$ for all of the constructs were greater than zero and the cross-validated redundancy coefficients $\left(\mathrm{F}^{2}\right)$ were greater than the recommended 0.10 level (Fornell \& Cha, 1994). The goodness of fit (GoF) index also exceeded the "large" threshold level of 0.36 (Wetzels et al., 2009) (Australia: 0.51; USA: 0.40; China: 0.59; India: 0.43). The summary results presented in Table 2 suggest the model was a good fit to the data in each of the four countries.

\section{[Insert Table 2 about here]}

The estimated paths in each country are shown in Table 3. The results provide substantial support for $\mathrm{H}_{1 \mathrm{a}}$ and $\mathrm{H}_{1 \mathrm{~b}}$, which suggested a positive relationship between perceived service fairness and cognitive and affective forms of trust. Specifically, service fairness significantly increased cognitive trust (Australia: $\beta=0.71, p<0.01$; USA: $\beta=0.62, p<0.01$; India: $\beta=$ 0.72, $\mathrm{p}<0.01$; China: $\beta=0.85, \mathrm{p}<0.01$ ) and affective trust (Australia: $\beta=0.52, \mathrm{p}<0.01$; USA: $\beta=0.49, p<0.01$; India: $\beta=0.76, p<0.01$; China: $\beta=0.85, p<0.01$ ). This suggests 
that customers who perceived high levels of service fairness were more likely to develop cognitive and affective trust in their provider.

$\mathrm{H}_{2}$, which suggested there was a positive relationship between cognitive trust and valuein-use, was not supported in Australia $(\beta=0.08, \mathrm{p}=0.10)$, but was supported in the other countries (USA: $\beta=0.22, p<0.05$; India: $\beta=0.21, p<0.01$; China: $\beta=0.40, p<0.01$ ). However, support was found for the suggested positive relationship between affective trust and value-in-use in all countries (Australia: $\beta=0.72, p<0.01$; USA: $\beta=0.63$, $p<0.01$; India: $\beta=0.61, p<0.01$; China: $\beta=0.54, p<0.01)$. Thus, value-in-use is influenced by customers' affective trust in their provider. $\mathrm{H}_{3 \mathrm{a}}$ which suggested a positive relationship between cognitive trust and customer engagement behaviors was supported in Australia ( $\beta=$ 0.17, $\mathrm{p}<0.01)$, India $(\beta=0.32, \mathrm{p}<0.01)$, and China $(\beta=0.21, \mathrm{p}<0.01)$, but was not significant in the USA $(\beta=0.06, p=0.21)$. However, the suggested relationship between affective trust and customer engagement behaviors was supported in each of the countries (Australia: $\beta=0.32, \mathrm{p}<0.01$; USA: $\beta=0.39, \mathrm{p}<0.01$; India: $\beta=0.26, \mathrm{p}<0.01$; China: $\beta=$ 0.19, $\mathrm{p}<0.01)$. This result suggests that affective trust plays a key role in customers' engagement behaviors. Customers' perceptions of value-in-use had a significant positive impact on customer engagement behaviors in each country, thereby supporting $\mathrm{H}_{4}$ (Australia: $\beta=0.36, p<0.01$; USA: $\beta=0.31, p<0.01$; India: $\beta=0.30, p<0.01$; China: $\beta=0.57, p<$ $0.01)$.

\section{[Insert Table 3 about here]}

\subsubsection{Post-hoc mediation analysis}

Post-hoc analysis was used to test the mediating effects of cognitive trust, affective trust, and value-in-use in service fairness and customer engagement behavior relationship. We used Preacher and Hayes's (2004) PROCESS method with 5000 bootstrapping resamples. Affective trust (Australia: indirect $\beta=0.17, \mathrm{LCI}=0.09, \mathrm{UCI}=0.27$; USA: indirect $\beta=0.18$, 
$\mathrm{LCI}=0.10, \mathrm{UCI}=0.28)$ and value-in-use (Australia: indirect $\beta=0.18, \mathrm{LCI}=0.10, \mathrm{UCI}=$ 0.27; USA: indirect $\beta=0.19, \mathrm{LCI}=0.11, \mathrm{UCI}=0.29)$ mediated the relationship between service fairness and customer engagement behaviors in Australia (direct effect: $\beta=0.18, p<$ 0.01 ) and the USA (direct effect: $\beta=0.24, \mathrm{p}<0.01$ ). For the Indian sample, only value-in-use (indirect $\beta=0.19, \mathrm{LCI}=0.05, \mathrm{UCI}=0.35$ ) mediated the relationship between service fairness and customer engagement behaviors (direct effect: $\beta=0.41, p<0.01$ ). In China, cognitive trust (indirect $\beta=0.10, \mathrm{LCI}=0.04, \mathrm{UCI}=0.18$ ), affective trust (indirect $\beta=0.10$, $\mathrm{LCI}=0.02, \mathrm{UCI}=0.18$ ), and value-in-use (indirect $\beta=0.20, \mathrm{LCI}=0.10, \mathrm{UCI}=0.32$ ) mediated the relationship between service fairness and customer engagement behaviors (direct effect: $\beta=0.50, \mathrm{p}<0.01$ ).

\subsection{Results of cross-country differences}

A multigroup analysis was also used to examine the moderating role culture had on these relationships. After establishing measurement invariance across the four countries using the MICOM procedure (Henseler et al., 2016), the relevant path coefficients were compared using multigroup analysis through the Welch-Satterthwaite approach (Sarstedt et al., 2011). Table 4 and Table 5 show the results of the multigroup analyses.

\section{[Insert Table 4 about here]}

$\mathrm{H}_{5}$, which suggested service fairness would have a greater influence on cognitive trust in collectivist countries, was partially supported, as the relationship was significantly stronger in China than in the USA or Australia. However, this was not true for the difference between India and the USA and Australia. Service fairness had a stronger influence on affective trust in the two collectivist countries (India and China) than it did in the two individualistic countries (Australia and the USA), providing support for $\mathrm{H}_{5 b}$. 
Hypothesis $\mathrm{H}_{6 a}$, which suggested cognitive trust would have a stronger influence on value-in-use for individualistic countries was not supported. Indeed, cognitive trust had a significantly greater influence on value-in-use in China than in either Australia or the USA. However, $\mathrm{H}_{6 \mathrm{~b}}$ was partially supported, as affective trust had a stronger influence on value-inuse in Australia than in China. $\mathrm{H}_{7 a}$ was not supported, as cognitive trust had a significantly greater influence on CEB in the collectivistic countries (China and India) than it did in one of the individualistic countries (USA). Affective trust had a stronger influence on CEBs in the USA than in China, providing partial support for $\mathrm{H}_{7 \mathrm{~b}}$. Finally, $\mathrm{H}_{8}$ was also partially supported as value-in-use had a stronger influence on CEBs in China than in the USA or Australia.

The post-hoc multigroup analysis was carried out by combining respondents from Australia and USA (individualist countries) into one group and respondents from India and China (collectivist countries) into another group. Table 6 presents the results of the path coefficients. The findings support $\mathrm{H}_{5}$, as service fairness had a stronger influence on cognitive trust and affective trust in collectivist countries than in individualist countries. $\mathrm{H}_{6}$ was not supported, as cognitive trust had significantly greater influence on value-in-use for collectivist countries than in individualist countries. No significant difference was observed in the effect affective trust had on value-in-use for collectivist and individualist countries. $\mathrm{H}_{7}$ was partially supported, as affective trust had a significantly greater influence on customer engagement behaviors in individualist countries than in collectivist countries. However, contrary to expectations, cognitive trust had a stronger influence on customer engagement behaviors in collectivist countries than in individualist countries. $\mathrm{H}_{8}$ was supported, as valuein-use had a stronger influence on customer engagement behavior in collectivist countries than in individualist countries. 


\section{Discussion and implications}

The study was undertaken to examine the relationships between service fairness and different forms of trust, value-in-use, and CEBs in two developed and two developing nations. Table 7 provides a summary of the hypotheses that were tested and the contributions made are discussed in subsequent sections.

\section{[Insert Table 7 about here]}

\subsection{Theoretical contributions}

Our research contributes to the fairness and trust literature by examining the impact service fairness had on cognitive and affective trust. This is a welcome addition to the literature given the lack of research into these trust dimensions (Zhu et al., 2013). This extends research on both service fairness and trust (Dirks \& Ferrin, 2002). We also contribute to the emerging CEB management literature by investigating types of CEBs (van Doorn et al., 2010). An important contribution is the use of multiple-item scales to measure and test Jaakkola and Alexander's (2014) four CEB types. The results suggest CEB is a higher-order construct and provide a more nuanced understanding of CEBs. The CEB structure was consistent across the individualist and collectivist countries included in this study. Consistent with Jaakkola and Alexander (2014), it seems customers who are engaged with their providers do contribute a wide range of resources. As a result, this research improved our understanding of CEBs and how firms can manage such CEBs effectively and efficiently. We also addressed the call for more research by identifying some customer-level psychological antecedents of CEB (van Doorn et al., 2010).

This study contributes to the value co-creation literature by identifying some immediate antecedents to value-in-use and testing their relationships across developed and developing markets, responding to a key research priority (Ostrom et al., 2015). More specifically, the examination of the relationships between forms of trust and ViU and CEB is a welcome 
addition to the growing literature on value co-creation. Strong support was found for the impact affective trust had on ViU and CEB in the developed and developing markets. This is consistent with suggestions that affective trust has more impact on CEBs than does cognitive trust (Zhu et al., 2013). The positive impact ViU had on CEB contributes to the suggestions that there is a need to identify the outcomes of ViU (Grönroos \& Voima, 2013).

Answering the call for more research in emerging markets (Dekimpe, 2009; Burgess \& Steenkamp, 2013), this study examined the various relationships in developed and developing markets and found there were stronger relationship between fairness and affective trust in developing markets, which was consistent with earlier suggestions (Aryee et al., 2002).

\subsection{Managerial implications}

The present study has several important managerial implications. An overarching implication is that CEBs are influenced by a number of factors, including service fairness, cognitive and affective trust and value-in-use. Consequently, attention should be paid to each of these constructs. More generally the model suggests ways to increase CEBs. In order to motivate customers in developed and developing markets to engage, service providers need to treat them fairly, build cognitive and affective trust and understand how they create valuein-use.

Managers should encourage actions that promote perceptions of service fairness in collectivist societies. Understanding sub dimensions of service fairness, e.g. interactional or procedural may highlight the emphasis for proper training and recruitment, especially when the service is delivered in the collectivist society. This may also include marketing strategies like deciding appropriate price points so that customers perceive them to be reasonable and commensurate with the level of service provided. Promoting fairness would in turn foster trust in the service provider. In the collectivist society, managers of a service firm should also focus on integrity and reliability (underlying cognitive trust) as they seem to motivate 
customers to engage in meaningful relations with the organization, which in turn shapes value co-creation. Customer engagement behavior as conceptualized in our work also incorporates advocacy for the service firm (e.g., social media, word-of-mouth), all of which should enhance brand reputation for the service provider. To achieve similar results (e.g., advocacy) in individualist societies, managers should focus on affective trust which seems to be driving customer engagement and value co-creation.

The CEB scale created in the study and used here provides practitioners with a tool to evaluate and assess customers' propensity to undertake CEBs. Given the consistency of the scale across two developed markets and two developing markets, it is likely to be generally useful. The CEB scale could also be used to segment customers based on their propensity to engage in different types of CEBs.

\subsection{Limitations and future research}

While this study provided useful theoretical and managerial insights, it is not free from limitations. First, while the sample was drawn to be representative, all online panels are nonprobability samples, suggesting some caution in making generalizations. Second, although the model was assessed in two developed and two developing markets, it would be advisable to replicate the study in other service settings. It seems that, since cognitive trust is based on shared values, its effect is more pronounced in collectivist cultures, where relational norms are more prominent, which is consistent with Chen et al.'s (2002) suggestion. The service setting (e.g., hotel) used in the study might also have encouraged such a mindset. Past research also supports distinct pathways (e.g., cognitive vs. affective) to persuasion for marketing communications in developing countries (Zarantonello, Jedidi, \& Schmitt 2013). Further, it is possible that some of the responses were motivated by people's personal culture orientation rather than national culture. For example, Sharma (2010) argued individuals from a collectivist society can demonstrate personal individualism. Some of our findings, like 
similar patterns of results for the USA and India support this. It is possible that, despite being a collectivist country, some Indian respondents were driven by personal individualism. Hence, future research might examine the impact customers’ personal values, age, gender and personal cultural orientations have on their perceptions of service fairness, trust, and customer engagement behavior relationships. Finally, a limitation of the current study was the use of cross-sectional design. A longitudinal design could be used to assess CEBs at different touch points to see if this provides additional insights (Bijmolt et al., 2010).

\section{References}

Adams, J. S. (1965). Inequity in social exchange. Advances in Experimental Social Psychology, 2, 267-299.

Agarwal, U. (2014). Linking justice, trust and innovative work behaviour to work engagement. Personnel Review, 43(1), 41-73.

Anderson, J. C., \& Gerbing, D. W. (1988). Structural equation modeling in practice: A review and recommended two-step approach. Psychological Bulletin, 103(3), 411-423.

Aryee, S., Budhwar, P. S., \& Chen, Z. X. (2002). Trust as a mediator of the relationship between organizational justice and work outcomes: Test of a social exchange model. Journal of Organizational Behavior, 23(3), 267-285.

Bijmolt, T. H., Leeflang, P. S., Block, F., Eisenbeiss, M., Hardie, B. G., Lemmens, A., \& Saffert, P. (2010). Analytics for customer engagement. Journal of Service Research, 13(3), 341-356.

Blau, P. M. (1964). Exchange and power in social life. Transaction Publishers.

Blocker, C. P. (2011). Modeling customer value perceptions in cross-cultural business markets. Journal of Business Research, 64(5), 533-540. 
Bowden, J. L. H. (2009). The process of customer engagement: A conceptual framework. Journal of Marketing Theory and Practice, 17 (1), pp. 63-74.

Brockner, J., De Cremer, D., van den Bos, K., \& Chen, Y. R. (2005). The influence of interdependent self-construal on procedural fairness effects. Organizational Behavior and Human Decision Processes, 96(2), 155-167.

Brodie, R.J., Hollebeek, L.D., Juric, B. \& Ilic, A. (2011). Customer engagement: conceptual domain, fundamental propositions, and implications for research. Journal of Service Research, 14(3), 252-271.

Buchan, N. R., Croson, R. T. A., \& Dawes, R. M. (2002). Swift neighbors and persistent strangers: A cross-cultural investigation of trust and reciprocity in social exchange. American Journal of Sociology, 108(1), 168-206.

Burgess, S. M., \& Steenkamp, J. B. E. (2013). Editorial: introduction to the special issue on marketing in emerging markets. International Journal of Research in Marketing, 30(1), 13.

Carr, C. L. (2007). The FAIRSERV model: Consumer reactions to services based on a multidimensional evaluation of service fairness. Decision Sciences, 38(1), 107-130.

Castaldo, S. (2007). Trust in Market Relationships, Edward Elgar Publishing, Northampton, MA.

Chen, C. C., Peng, M. W., \& Saparito, P. A. (2002). Individualism, collectivism, and opportunism: A cultural perspective on transaction cost economics. Journal of Management, 28(4), 567-583.

Clayton, S., \& Opotow, S. (2003). Justice and identity: Changing perspectives on what is fair. Personality and Social Psychology Review, 7(4), 298-310.

Clemmer, E. C., \& Schneider, B. (1996). Fair service. Advances in Services Marketing and Management, 5, 109-126. 
Cohen, A., \& Avrahami, A. (2006). The relationship between individualism, collectivism, the perception of justice, demographic characteristics and organisational citizenship behaviour. The Service Industries Journal, 26(8), 889-901.

D’Arpizio, C., Levato, F., Zito, D., \& de Montgolfier, J. (2015). Luxury goods worldwide market study. A time to act: How luxury brands can rebuild to win. Retrieved from http://www.bain.com/publications/articles/luxury-goods-worldwide-market-study-winter2015.aspx

Dekimpe, M. G. (2009). From the (new) editor. International Journal of Research in Marketing, 26(4), 259-260

De Matos, C. A., \& Rossi, C. A. V. (2008). Word-of-mouth communications in marketing: a meta-analytic review of the antecedents and moderators. Journal of the Academy of Marketing Science, 36(4), 578-596.

Devlin, J.F., Kumar Roy, S., \& Sekhon, H. (2014). Perceptions of fair treatment in financial services: Development, validation and application of a fairness measurement scale. European Journal of Marketing, 48(7/8), 1315-1332.

DeWitt, T., Nguyen, D. T., \& Marshall, R. (2008). Exploring customer loyalty following service recovery the mediating effects of trust and emotions. Journal of Service Research, 10(3), 269-281.

Dirks, K. T., \& Ferrin, D. L. (2002). Trust in leadership: meta-analytic findings and implications for research and practice, Journal of Applied Psychology, 87(4), 611-628.

Edvardsson, B., Tronvoll, B., \& Gruber, T. (2011). Expanding understanding of service exchange and value co-creation: a social construction approach. Journal of the Academy of Marketing Science, 39(2), 327-339.

Falk, R. F., \& Miller, N. B. (1992). A primer for soft modeling. University of Akron Press: Akron $\mathrm{OH}$. 
Fischer, R. (2013). Belonging, status, or self-protection? Examining justice motives in a three-level cultural meta-analysis of organizational justice effects. Cross-Cultural Research, 47(1), 3-41.

Fornell, C., \& Cha, J. (1994). Partial least squares. Advanced Methods of Marketing Research, 407(3), 52-78.

Fornell, C., \& Larcker, D. F. (1981). Structural equation models with unobservable variables and measurement error: Algebra and statistics. Journal of Marketing Research, 18(3), 382-388.

Fukuyama, F. (1995). Trust: The Social Virtues and the Creation of Prosperity. New York: Free Press.

Gremler, D. D., Gwinner, K. P., \& Brown, S. W. (2001). Generating positive word-ofmouth communication through customer-employee relationships. International Journal of Service Industry Management, 12(1), 44-59.

Grönroos, C. \& Voima, P. (2013). Critical service logic: making sense of value creation and co-creation. Journal of the Academy of Marketing Science, 41(2), 133-150.

Hair, J. F., Black, W. C., Babin, B. J., Anderson, R. E., \& Tatham, R. L. (2006). Multivariate data analysis 6th Edition. Pearson Education: Englewood Cliffs, NJ.

Hair, J. F., Ringle, C. M., \& Sarstedt, M. (2011). PLS-SEM: Indeed a silver bullet. Journal of Marketing Theory and Practice, 19(2), 139-152.

Harms, P. D., Bai, Y., \& Han, G. H. (2016). How leader and follower attachment styles are mediated by trust. Human Relations, doi: 10.1177/0018726716628968.

Hayashi, Y., \& Sekiguchi, T. (2006). Collective justice perceptions in group-oriented cultures: Proposal of a new construct. Japanese Journal of Administrative Science, 19(3), 207-219. 
Henseler, J., Ringle, C. M., \& Sarstedt, M. (2016). Testing measurement invariance of composites using partial least squares. International Marketing Review, 33(3), 405-431.

Hollebeek, L. D., Srivastava, R. K., \& Chen, T. (2016). SD logic-informed customer engagement: integrative framework, revised fundamental propositions, and application to CRM. Journal of the Academy of Marketing Science, 1-25.

Holmvall, C. M., \& Bobocel, D. R. (2008). What fair procedures say about me: Selfconstruals and reactions to procedural fairness. Organizational Behavior and Human Decision Processes, 105(2), 147-168.

Hoyer, W. D., Chandy, R., Dorotic, M., Krafft, M., \& Singh, S. S. (2010). Consumer cocreation in new product development. Journal of service research, 13(3), 283-296.

Jaakkola, E., \& Alexander, M. (2014). The role of customer engagement behavior in value co-creation a service system perspective. Journal of Service Research, 17(3), 247-261.

JLL Real Views (2016). Australia's hotels reach for the stars. Retrieved from http://www.jllrealviews.com/places/australias-hotels-reach-stars/.

Johnson, D. \& Grayson, K. (2005). Cognitive and affective trust in service relationships. Journal of Business Research, 58(4), 500-507.

Khazanchi, S., \& Masterson, S. S. (2011). Who and what is fair matters: A multi-foci social exchange model of creativity. Journal of Organizational Behavior, 32(1), 86-106.

Knox, A. (2008). Gender desegregation and equal employment opportunity in Australian luxury hotels: Are we there yet?. Asia Pacific Journal of Human Resources, 46(2), 153-172.

Kumar Ranganathan, S., Madupu, V., Sen, S., \& R. Brooks, J. (2013). Affective and cognitive antecedents of customer loyalty towards e-mail service providers. Journal of Services Marketing, 27(3), 195-206. 
Lewicki, R.J. \& Bunker, B.B. (1995). Trust in relationships: a model of trust development and decline, in Bunker, B.B. and Rubin, J.Z. (Eds), Conflict, Cooperation, and Justice, Jossey-Bass, San Francisco, CA, 133-173.

Lewicki, R.J., Wiethoff, C. and Tomlinson, E. (2005) What Is the Role of Trust in Organizational Justice? In: Greenberg, J. and Colquitt, J., Eds., Handbook of Organizational Justice: Fundamental Questions about Fairness in the Workplace, Lawrence Erlbaum Associates, Mahwah, 247-270.

Lind, E. A., \& Tyler, T. R. (1988). The social psychology of procedural justice. Plenum Press: New York, NY.

Lindell, M. K., \& Whitney, D. J. (2001). Accounting for common method variance in cross-sectional research designs. Journal of Applied Psychology, 86(1), 114-121.

Macdonald, E. K., Wilson, H., Martinez, V., \& Toossi, A. (2011). Assessing value-in-use: A conceptual framework and exploratory study. Industrial Marketing Management, 40(5), 671-682.

Maheswaran, D., \& Shavitt, S. (2000). Issues and New Directions in Global Consumer Psychology. Journal of Consumer Psychology, 9(2), 59-66.

Malhotra, N. K., Agarwal, J., \& Peterson, M. (1996). Methodological issues in crosscultural marketing research: A state-of-the-art review. International Marketing Review, 13(5), 7-43.

Marketing Science Institute. (2016). 2016-2018 research priorities. Retrieved from http://www.msi.org/research/2016-2018-research-priorities/

Mayer, R. C., \& Davis, J. H. (1999). The effect of the performance appraisal system on trust for management: A field quasi-experiment. Journal of Applied Psychology, 84(1), 123136. 
McAllister, D. J. (1995). Affect-and cognition-based trust as foundations for interpersonal cooperation in organizations. Academy of Management Journal, 38(1), 24-59.

Mikula, G., Scherer, K. R., \& Athenstaedt, U. (1998). The role of injustice in the elicitation of differential emotional reactions. Personality and Social Psychology Bulletin, 24(7), 769-783.

Miller, J. G. (1997). Culture and the self: Uncovering the cultural grounding of psychological theory. In J. G. Snodgrass \& R. L. Thompson (Eds.), The self across psychology (pp. 217-231). New York: New York Academy of Sciences.

Morgan, R. M., \& Hunt, S. D. (1994). The commitment-trust theory of relationship marketing. Journal of Marketing, 58(3), 20-38.

Murphy-Berman, V., \& Berman, J. J. (2002). Cross-Cultural Differences in perceptions of distributive justice: A comparison of Hong Kong and Indonesia. Journal of Cross-Cultural Psychology, 33(2), 157-170.

Oliver, R. (1997). Equity: How consumers interpret fairness. Satisfaction: A behavioral perspective on the consumer, 193-215.

Ostrom, A.L., Parasuraman, A., Bowen, D.E., Patricio, L., Voss, C.A. \& Lemon, K., (2015), Service research priorities in a rapidly changing context, Journal of Service Research, $18(2), 127-159$.

Pansari, A. \& Kumar, V. (2016), Customer engagement: the construct, antecedents, and consequences, Journal of the Academy of Marketing Science, 1-18.

PRNewswire (2016). The global luxury hotels market to 2019. Retrieved from https://www.radiantinsights.com/research/the-global-luxury-hotels-market-to-2019.

Preacher, K. J., \& Hayes, A. F. (2004). SPSS and SAS procedures for estimating indirect effects in simple mediation models. Behavior research methods, instruments, \& computers, 36(4), 717-731. 
Podsakoff, P. M., MacKenzie, S. B., Lee, J. Y., \& Podsakoff, N. P. (2003). Common method biases in behavioral research: A critical review of the literature and recommended remedies. Journal of Applied Psychology, 88(5), 879-903.

Ranjan, K. R., \& Read, S. (2016). Value co-creation: Concept and measurement. Journal of the Academy of Marketing Science, 44(3), 290-315.

Ringle, C. M., Wende, S., \& Becker, J. M. (2015). SmartPLS 3. Boenningstedt: SmartPLS GmbH, http://www. smartpls.com.

Roy, S. K., Devlin, J. F., \& Sekhon, H. (2015). The Impact of fairness on trustworthiness and trust in banking. Journal of Marketing Management, 31(9-10), 996-1017.

Sarstedt, M., Henseler, J., \& Christian, M. (2011). Multigroup Analysis in Partial Least Squares (PLS) Path Modeling: Alternative Methods and Empirical Results, in Marko Sarstedt, Manfred Schwaiger,Charles R. Taylor (ed.) Measurement and Research Methods in International Marketing (Advances in International Marketing, Volume 22) Emerald Group Publishing Limited: Bingley, UK, 195 - 218.

Seiders, K., \& Berry, L. L. (1998). Service fairness: What it is and why it matters. Academy of Management Executive, 12(2), 8-20.

Sekhon, H., Ennew, C., Kharouf, H., \& Devlin, J. (2014). Trustworthiness and trust: Influences and implications. Journal of Marketing Management, 30(3-4), 409-430.

Sekhon, H., Roy, S., Shergill, G., \& Pritchard, A. (2013). Modelling trust in service relationships: A transnational perspective. Journal of Services Marketing, 27(1), 76-86.

Sharma, P. (2010). Measuring personal cultural orientations: scale development and validation. Journal of the Academy of Marketing Science, 38(6), 787-806.

Sirdeshmukh, D., Singh, J., \& Sabol, B. (2002). Consumer trust, value, and loyalty in relational exchanges. Journal of Marketing, 66(1), 15-37. 
Skitka, L. J. (2003). Of different minds: An accessible identity model of justice reasoning. Personality and Social Psychology Review, 7(4), 286-297.

Soper, D.S. (2014). A-priori sample size calculator for structural equation models [software]. Available from http://www.danielsoper.com/statcalc.

Taylor, D. M., Wright, S. C., Moghaddam, F. M., \& Lalonde, R. N. (1990). The personal/group discrimination discrepancy perceiving my group, but not myself, to be a target for discrimination. Personality and Social Psychology Bulletin, 16(2), 254-262.

Tomlinson, E. C., \& Mayer, R. C. (2009). The role of causal attribution dimensions in trust repair. Academy of Management Review, 34(1), 85-104.

Törnblom, K. Y., \& Vermunt, R. (1999). An integrative perspective on social justice: Distributive and procedural fairness evaluations of positive and negative outcome allocations. Social Justice Research, 12(1), 39-64.

Tyler, T. R. \& Lind, E. A. (1992). A relational model of authority in groups. Advances in Experimental Social Psychology, 25, 115-191.

Vargo, S. L. \& Lusch, R. F. (2016). Institutions and axioms: an extension and update of service-dominant logic. Journal of the Academy of Marketing Science, 44(1), 5-23.

van Doorn, J., Lemon, K.N., Mittal, V., Nass, S., Pick, D., Pirner, P. \& Verhoef, P.C. (2010). Customer engagement behavior: Theoretical foundations and research directions. Journal of Service Research, 13(3), 253-266.

Verhoef, P. C., Reinartz, W. J. \& Krafft, M. (2010), Customer engagement as a new perspective in customer management, Journal of Service Research, 13(3), 247-252.

Verleye, K., Gemmel, P. \& Rangarajan, D., (2016). Engaged customers as job resources or demands for frontline employees? Journal of Service Theory and Practice, 26(3), 363-383. 
Wetzels, M., Odekerken-Schröder, G., \& Van Oppen, C. (2009). Using PLS path modeling for assessing hierarchical construct models: Guidelines and empirical illustration. MIS quarterly, 33(1), 177-195.

Wu, L. Y., Chen, K. Y., Chen, P. Y., \& Cheng, S. L. (2014). Perceived value, transaction cost, and repurchase-intention in online shopping: A relational exchange perspective. Journal of Business Research, 67(1), 2768-2776.

Yamagishi, T. (1988). Exit from the group as an individualistic solution to the free rider problem in the United States and Japan. Journal of Experimental Social Psychology, 24(6), 530-542.

Yang, J., Mossholder, K. W., \& Peng, T. K. (2009). Supervisory procedural justice effects: The mediating roles of cognitive and affective trust. The Leadership Quarterly, 20(2), 143154.

Yang, F. X., \& Lau, V. M. (2015). Luxury” hotel loyalty-a comparison of Chinese Gen X and $\mathrm{Y}$ tourists to Macau. International Journal of Contemporary Hospitality Management, 27(7), 1685-1706.

Zarantonello, L., Jedidi, K., \& Schmitt, B. H. (2013). Functional and experiential routes to persuasion: An analysis of advertising in emerging versus developed markets. International Journal of Research in Marketing, 30(1), 46-56.

Zhu, Y, Q. \& Chen, H. G. (2012). Service fairness and customer satisfaction in internet banking. Internet Research, 22(4), 482.

Zhu, W., Newman, A., Miao, Q., \& Hooke, A. (2013). Revisiting the mediating role of trust in transformational leadership effects: Do different types of trust make a difference? The Leadership Quarterly, 24(1), 94-105. 